\title{
Farklı Pedolojik Özelliklere Sahip Toprakların, Morfolojik, Mineralojik ve Bazı Mühendislik Özellikleri
}

\author{
Orhan DENGİ, Fatma Esra GÜRSOY* \\ Ondokuz Mayls Üniversitesi, Ziraat Fakültesi, Toprak Bilimi ve Bitki Besleme Bölümü, Samsun, TÜRKIYYE
}

\begin{tabular}{ll}
\hline \multicolumn{1}{c}{ Geliş Tarihi/Received: 18.05 .2018} & Kabul Tarihi/Accepted: 28.11 .2018 \\
\hline ORCID ID (Yazar sirasina göre / by author order) \\
\hline (Dorcid.org/0000-0002-0458-6016 (D) orcid.org/0000-0003-0012-3943 \\
*Sorumlu Yazar/Corresponding Author: esra.sarioglu@omu.edu.tr
\end{tabular}

Öz: Bu çalışma kapsamında, aynı ana materyal üzerinde farklı pedolojik gelişime sahip olan üç toprak profilinin; morfolojik, minerolojik, fiziksel ve kimyasal özellikleri belirlenerek, fiziksel özellikleri ile minerolojik özellikleri arasındaki ilişkileri incelenmiştir. Çalışma sonucuna göre, topraklar alt grup düzeyde Vertik Ustorthent, Typic Haplustept ve Vertic Calciustept olarak sınıflandırılmıștır. Mineralojik analiz sonuçları; 2:1 tipi genișleyen smektit grubunda yer alan montmorillonit'in baskın kil minerali olduğunu, az miktarda kaolinit ve nantronit kil minerallerinin bulunduğunu göstermiştir. Toprakların genetik horizonlarında fiziksel özelliklerden toprakların likit limit ve plastiklik indeksi değerleri sırasıyla \% 48-\% 63 ve \% 25-\% 37 arasında değişim göstermektedir. Yüzey horizonlarda en yüksek likit limit ve plastiklilik indeks değerine Vertik Ustorthent topraklar, en düşük değere ise Vertic Calciustept topraklar sahip oldukları belirlenmiştir. Birleştirilmiş toprak sınıflama sistemi (Unified Soil Classification System, USCS)'ne göre ise tüm topraklar yüksek plastisiteli inorganik killer (CH) ve yüksekten orta dereceye doğru plastisitede inorganik killer (CL) olarak sınıflandırılmıştır. Ayrıca mineralojik testlerin sonuçları, indeks özelliklerinin sonucu elde edilen değerler ve șișme değerlendirmesi ile elde edilen genișleyebilir toprak özellikleri arasında uyum olduğu tespit edilmiştir. Bunun yanında, pedolojik gelişim özellikle cambik horizon oluşumu toprakların mineralojik ve fiziksel özellikleri üzerinde fazla bir etkisinin olduğu söylenemez.

Anahtar Kelimeler: Atterberg limitler, mineroloji, toprak sinıflamas1, Entisol, Inceptisol

\section{Morphological, Mineralogical and Some Engineering Properties of Soil with Different Pedalogical Properties}

\begin{abstract}
In this study, the morphological, mineralogical, physical and chemical properties of three soil profiles, having different pedological development on the same parent material, were determined and relationships between their physical properties and mineralogical properties were investigated. According to this study's results, three soil profiles were classified as Vertik Ustorthent, Typic Haplustept and Vertic Calciustept. The results of mineralogical analysis showed that montmorillonite in the 2:1 type expanding smectite group is the dominant clay mineral and there is a small amount of kaolinite and nontronite clay minerals. Liquid limit and plastic limit of genetic horizons of soils were determined between $48-63 \%$ and $25-37 \%$, respectively. The highest liquid limit and plastic limit values in surface horizon were found in Vertik Ustorthent whereas, the lowest values were determined for Vertic Calciustept. According to USCS (Unified Soil Classification System) classification, all soils were classified as high plasticity, inorganic clay $(\mathrm{CH})$ and as moderate plasticity, inorganic clay (CL). In addition, mineralogical test results, values obtained as a result of index properties, and swelling evaluations obtained with the extension of soil properties has been found to be compatible. Besides, pedalogical development (cambic horizon) cannot be said to have much effect on the mineralogical and physical properties of soils.
\end{abstract}

Keywords: Atterberg limits, clay mineral, soil classification, Entisol, Inceptisol 


\section{Giriş}

Günümüzde çeşitli tarım ve mühendislik amaçlar için toprakların; likit limit, plastik limit plastiklik, şişme ve büzülme potansiyeli gibi temel mekaniksel özelliklerine zaman zaman ihtiyaç duyulmaktadır. Özellikle şişme potansiyeli, bitki yetiştiriciliği ve toprak yönetimi bakımından oldukça önemlidir. Şişme büzülme süreci içinde profil derinliğinde ortaya çıkan çatlamalar; genç fidelerin, bitki köklerinin zarar görmesine ve toprağın su ve hava dengesinin bozulmasına, nem kaybının artmasına, sulama suyunun etkinliğinin azalmasına ve toprağın strüktürel durumunun kötüleşmesine yol açabilir (Sönmez ve Öztaş, 1988). Bu nedenle, Canbolat ve Öztaş, (1997) topraktaki bitki kök ve gövde gelişimini etkileyen bu mekaniksel davranışların bilinmesi, tarımsal yönetim uygulamalarında gerekli önlemlerin alınması bakımından önemli olduğunu belirtmişlerdir. Ayrıca, toprak nem içeriğindeki değişimlerin sebep olduğu şişmebüzülme veya toprak kütlesindeki hacimsel değişim, toprakta mevcut kil mineralinin tipi ile de yakın bir ilişki içerisindedir (Mbagwu ve Abeh, 1998).

Toprakların kendilerine özgü kazanmış oldukları karakteristik özellikler, kil fraksiyonlarının miktarına, çeşidine ve mineral kompozisyonuna göre değişim göstermektedir. Toprağın kimyasal, fiziksel ve fiziko-kimyasal yönden en aktif ve en önemli yap1 maddelerini mineral ve organik kolloidler oluşturmaktadır. Mineral kolloidler olarak bilinen killer, çeşitli tiplere ayrılmaktadır. Kil minerallerinin çok ince zerreler halinde bulunmaları, kristal ve kimyasal yapı yönünden temelde birbirlerine benzemelerine rağmen, birbirlerinden katyon değişimi ve su tutma kapasitesi, özgül yüzey alanı, likitlik, plastiklik, şişme-büzülme gibi özellikler yönünden çok büyük farklılıklar göstermektedir. Atterberg (1911) de ilk olarak ortaya koymuş olduğu toprakların likitlik, plastiklik, şişme-büzülme limit özellikleri gibi konularda yapmış olduğu çalışmalar sonrasında; kil minerallerinin plastikliğini etkileyen mineral kompozisyonu, şekil ve boyut dağılımı, killer ile su ve çözünmüş tuzlar arasındaki etkileşimi, kil oluşumu gibi durumları değerlendirmek amacıyla toprakta birçok çalışmalar yapılmış ve yapılmaya devam etmektedir. Ayrıca, Casagrande (1958) ise toprak kartını yayınlaması sonrasında, Dumbleton ve West (1966) dünyanın çok değişik bölgelerine ait topraklarda kil miktarı ve tipi ile plastik ve likit limit arasındaki ilişkiyi çalışmışlardır. Benzer şekilde Gürsoy ve Dengiz (2018) Samsun ekolojik koşulları altında, farklı iki ana materyal (bazalt ve marn) üzerinde oluşmuş vertisol toprakların kil içerikleri ile plastik ve likit limit arasındaki ilişkiyi incelemişler; çalışma sonucunda, simektit kil minerallerini fazla düzeyde içeren çalışma alanına ait toprakların, likit limit ve plastiklik indeksi değerlerinin sirasıyla \% 53-70 ve \% 27-40 arasında değişim gösterdiğini belirlemişler ve Birleştirilmiş Toprak Siniflama Sistemi (Unified Soil Classification System, USCS)'ne göre ise tüm topraklar yüksek plastisiteli inorganik killer $(\mathrm{CH})$ olarak sınıflandırılmıştır.

Kil mineralleri; sahip oldukları özgül yüzey alanı, katyon değişimi, besin elementlerinin adsorpsiyonu gibi özellikleri yönünden toprak kimyası ve bitki beslemeyi, hava ve su geçirgenliği, şişme-büzülme, strüktür oluşumu yönünden toprak fiziğini, toprak işleme ve tavı yönünden toprak amenajmanını doğrudan ilgilendirmektedir. Topraktaki mekanik özellikleri ise özellikle organik madde içeriği, kil içeriği ve bunlara bağlı olarak gelişen strüktür dayanıklılığı ile yakından ilişkilidir (Sowers, 1965; Baver, 1966). Toprakların sahip oldukları mekanik özellikler ve kil içeriği arasında ise yine önemli pozitif ilişkiler tespit edilmiştir (Le Villio ve ark., 2002). Smith ve ark. (1985), toprakların fiziksel ve kimyasal özellikleri ile mekaniksel özellikleri arasındaki ilişkileri araştırmak üzere yapmış oldukları bir çalışmada; organik madde ve kil içeriği, özgül yüzey alanı, katyon değişim kapasitesi ve higroskopik su değerleri ile doğrusal uzama katsayısı değerleri arasında önemli pozitif ilişkiler saptamışlardır. Araştırıcılar, kireç içeriği ile doğrusal uzama katsayısı değerleri arasında herhangi bir ilişkinin bulunmadığını kaydetmişlerdir. Toprağın kıvam limitleri ile bazı fiziksel ve kimyasal özellikleri arasındaki ilişkileri belirlenmesine yönelik Türkiye'de ise Canbolat ve Öztaş (1997), kıvam limitlerini kullanarak toprak strüktürüne en az zararla, toprak işleme için en uygun nem aralığını saptamak amacıyla bir çalışma gerçekleştirmişlerdir. Çalışmada, kil içeriği, organik madde miktarı, kireç içeriği, katyon değişim kapasitesi ile likit limit ve plastik limit arasında önemli pozitif ve kum içeriği ile önemli negatif ilişkiler tespit etmişlerdir. Ayrıca Boyraz ve Sarı (2012) ise, Tekirdağ çevre yolunun İstanbul girişinden, Bağlar mevkii sırtları ve Muratlı çevre yolu kavşağı arasında kalan arazilerin bazı fiziksel ve mekanik özelliklerini saptayarak, toprak taksonomisine göre sınıflamasını yapmışlardır. Toprak yapan faktörlerle araştırılan 10 profilin fiziksel ve kimyasal özellikleri belirlenerek profil tanımlamaları yapılmıştır. Yapılan değerlendirmeler sonucunda, bünyelerinin genelde killi ve killi tınlı bir yapıda olduğu tespit edilmiştir. Zemin incelemeleri ise USCS'ye göre yüksek plastisiteli kil ve düşük plastisiteli kil olduğunu belirlemişlerdir. Yine, Canbolat ve ark. (1999), 
farklı ana materyal üzerinde oluşmuş toprakların pedolojik özellikleri ile kıvam limitleri ve şişmebüzülme karakteristiklerinin toprak derinliği ile değişimini incelemişler ve ana materyali lakustrin olan profilin mekaniksel özelliklerinin profil derinliğinde bir artış gösterdiğini, ana materyali bazalt ve kireçli aluviyal olan profillerin $\mathrm{C}$ horizonunda tespit edilen mekanikse özelliklerin diğer horizonların mekaniksel özelliklerinden daha düşük değerlere sahip olduğunu tespit etmişlerdir.

$\mathrm{Bu}$ çalıșma kapsamında, aynı ana materyal üzerinde farklı pedolojik gelişime sahip olan üç toprak profilinin morfolojik, mineralojik, fiziksel ve kimyasal özellikleri belirlenerek, fiziksel özellikleri ile mineralojik özellikleri arasındaki ilişkileri incelenmiştir.

\section{Materyal ve Yöntem}

Araştırma, Orta Karadeniz Bölgesi içerisinde yer alan Samsun ilinde gerçekleştirilmiş olup; araştırma alanı, Atakum ilçesi yerleşim alanının mücavir alan sınırı içerisinde kalan ve Samsun-Ankara karayoluna cephe olan üzerinde Yeşilkent beldesi, Toybelen, Beypınarı, Kuşçulu ve Çivril köy ve mahallelerinin yer aldığı alan içerisinde seçilmiştir. Çalışma alanında marn ana materyal üzerinde oluşmuş üç toprak profili incelenmiştir (Tablo 1).

Toprak profillerinden genetik horizon esasına göre morfolojik tanımlamalar yapılarak bozulmuş ve bozulmamış toprak örnekleri alınmıştır. Arazide toprakların morfolojik özelliklerinin incelenmesi amacıyla dikkate alınan kriterler, örneklemeler ve sınıflandırma için Anonymous (1993, 1999) kullanılmıştır.

Tablo 1. Seçilen toprak profillere ait çevresel özellikler

\begin{tabular}{|c|c|c|c|c|c|c|}
\hline \multirow[t]{2}{*}{ Topraklar } & \multicolumn{2}{|c|}{$\begin{array}{c}\text { Koordinat } \\
\text { (UTM- m, Zone 37) }\end{array}$} & \multirow{2}{*}{$\begin{array}{c}\text { Eğim } \\
(\%)\end{array}$} & \multirow{2}{*}{$\begin{array}{l}\text { Yükseklik } \\
\text { (m) }\end{array}$} & \multirow[t]{2}{*}{ Ana materyal } & \multirow[t]{2}{*}{ Arazi kullanım } \\
\hline & Kuzey & Doğu & & & & \\
\hline Vertic Ustorthent & 4575627 & 271019 & $20-30$ & 164 & Marn & Kuru tarım \\
\hline Typic Haplustept & 4573568 & 269387 & $6-12$ & 138 & Marn & Kuru tarım \\
\hline Vertic Calciustept & 4573459 & 272518 & $6-12$ & 110 & Marn & Kuru tarım \\
\hline
\end{tabular}

Toprak örneklerinin bünye analizi, Bouyoucous (1951) yöntemine göre; $\mathrm{pH}, \quad$ 1:5 toprak-su süspansiyonunda cam elektrotlu $\mathrm{pH}$ metre (Anonymous, 1992); elektriksel iletkenlik (EC), 1:5 toprak-su süspansiyonunda (Anonymous, 1992); organik madde, Jackson (1958)'a göre, kireç $\left(\mathrm{CaCO}_{3}\right)$, Çağlar (1958)'a göre; katyon değişim kapasitesi (KDK) ve değişebilir katyonlar Anonymous (1992)'a göre; hacim ağırlığı ise, bozulmuş örneklerde Blake ve Hartage (1986) tarafından bildirilen esaslara göre belirlenmiştir. Atterberg limitleri (likit limit, plastik limit, büzülme limiti) Casagrande (1958) ve Head (1984) dikkate alınarak yapılmıştır. Ayrıca, plastiklik indeksi, likit limitten plastik limitin çıkarılmasıyla; kil aktivitesi ise plastiklik indeksinin, kil yüzdesine oranlanmasıyla hesaplanmıştır (Skempton, 1953). Elde edilen likit limit ve plastiklik indeksi değerlerinde Casagrande (1958) plastiklik kartı kullanılarak sınıflandırılması yapılmıştır.

Toprakların mineralojik analizlerinde toprak örnekleri toz haline getirildikten sonra kil dişı minerallerin belirlenmesi amaciyla preparatlar hazırlanmış ve X-Işını Difraksiyonu (XRD) eğrileri elde edilmiştir (Saka, 1997). Toz örneklerin kil farksiyıonları ( $<2 \mu \mathrm{m}$ tane boyu) sedimentasyonla ayrıldıktan sonra santrifüj ile çökertilmiş ve preparatlar hazırlanmıştır. Kil mineral türleri, bu preparatların havada kurutulmuş, etilen glikol ile doyurulmuş ve firınlama işlemleri sonrasında elde edilen XRD diyagramları Whitting ve Allardice (1986)'e göre incelenmiştir. XRD çekimleri Maden Tetkik Arama Genel Müdürlüğü XRD laboratuvarında RIGAKU model X-Işını difraktometer cihazı ile gerçekleşmiştir.

\section{Bulgular ve Tartışma}

\subsection{Toprakların morfolojik, fiziksel, kimyasal özellikleri ve sınıflandırılması}

Toprakların bazı fiziksel, kimyasal ve morfolojik özellikleri Tablo 2'de verilmiştir. Vertic Ustorthent olarak siniflandirılan toprakların pH's1 7.90 ile 8.58 arasında değişmekte olup, hafif alkalin reaksiyonludur. Toprakların kireç içerikleri yüzeyde \% 7.1 iken, derinlikle artmakta ve \% 69'lara ulaşmaktadır. Bu durum toprak rengine de yansımakta olup yüzeyde value değerleri 3 iken, derine doğru arttığ görülmektedir. Yüzey katmanda kil miktarının \% 50'lerde olması şişebilen killer içermesi nedeniyle çatlamalar görülmektedir. Ayrıca, toprakların tarımsal faaliyetler sonucu pulluk katı altında sıkışmış (taban taşı) bir kat olduğu, morfolojik inceleme sonucu belirlenmiştir. Profil içerisindeki organik madde miktarı \% 0.5 ile \% 2.4 
Tablo 2. Çalışma alanı topraklarının bazı fiziksel kimyasal ve morfolojik özellikleri*

\begin{tabular}{|c|c|c|c|c|c|c|c|c|c|c|}
\hline \multirow{2}{*}{ Horizon } & \multirow{2}{*}{$\begin{array}{c}\text { Derinlik } \\
(\mathrm{cm})\end{array}$} & \multirow{2}{*}{$\mathrm{pH}$} & \multirow{2}{*}{$\begin{array}{c}\mathrm{EC} \\
\left(\mathrm{dS} \mathrm{m}^{-1}\right) \\
\end{array}$} & \multirow{2}{*}{$\begin{array}{c}\mathrm{CaCO}_{3} \\
(\%)\end{array}$} & \multirow{2}{*}{$\begin{array}{l}\mathrm{OM} \\
(\%)\end{array}$} & \multicolumn{2}{|c|}{ Renk } & \multirow{2}{*}{ Kivam } & \multirow{2}{*}{ Strüktür } & \multirow{2}{*}{$\begin{array}{c}\text { Özel } \\
\text { görünüm }\end{array}$} \\
\hline & & & & & & Kuru & Nemli & & & \\
\hline \multicolumn{11}{|c|}{ Profil-1/Vertic Ustorthent / Vertic Leptosol } \\
\hline Ap & $0-16$ & 7.90 & 0.54 & 7.1 & 2.4 & $2,5 \mathrm{Y} 4 / 3$ & 2,5 Y $3 / 3$ & $\mathrm{~h}$ st pt & $2 \mathrm{cgr}$ & Çatlaklık \\
\hline Ad & $16-35$ & 8.07 & 0.40 & 8.2 & 3.3 & 2,5 Y $4 / 3$ & 2,5 Y $3 / 3$ & sh st pt & $2 \mathrm{msbk}$ & Sıkışmış kat \\
\hline $\mathrm{AC}$ & $35-61$ & 8.27 & 0.36 & 23.0 & 1.5 & 2,5 Y $5 / 4$ & 2,5 Y $4 / 4$ & sh st pt & $1 \mathrm{msbk}$ ve $\mathrm{m}$ & - \\
\hline $2 \mathrm{Ck}$ & $61+$ & 8.58 & 0.35 & 69.0 & 0.5 & $2,5 \mathrm{Y} 4 / 4$ & 2,5 Y $5 / 4$ & sh st pt & $\mathrm{m}$ & Kireç miselleri \\
\hline \multicolumn{11}{|c|}{ Profil-2/ Typic Haplustept / Haplic Cambisol } \\
\hline A & $0-28$ & 7.78 & 0.20 & 11.6 & 2.9 & $2,5 \mathrm{Y} 4 / 4$ & $2,5 \mathrm{Y} 4 / 4$ & h st pt & $3 \operatorname{cgr}$ & - \\
\hline Bw & $28-68$ & 8.47 & 0.17 & 29.8 & 1.5 & 2,5 Y 5/6 & $2,5 \mathrm{Y} 4 / 4$ & sh st pt & $2 \mathrm{msbk}$ & $\begin{array}{l}\text { Strüktürel } \\
\text { gelisim }\end{array}$ \\
\hline $\mathrm{Ck}$ & $68-97$ & 8.60 & 1.81 & 27.3 & 0.1 & 2,5 Y $6 / 4$ & 2,5 Y $5 / 6$ & sh st pt & $\mathrm{m}$ & Kireç miselleri \\
\hline $\mathrm{Cr}$ & $97+$ & 8.58 & 1.47 & 23.8 & 0.1 & 2,5 Y $6 / 4$ & 2,5 Y $5 / 6$ & sh st pt & $\mathrm{m}$ & \\
\hline \multicolumn{11}{|c|}{ Profil-3/ Vertic Calciustept / Calcaric Cambisol } \\
\hline A & $0-24$ & 7.92 & 0.34 & 5.2 & 1.6 & $2,5 \mathrm{Y} 4 / 3$ & $2,5 Y 3 / 3$ & sh st pt & $2 \operatorname{cgr}$ & Çatlaklık \\
\hline Bw & $24-68$ & 8.14 & 0.28 & 4.1 & 1.1 & $2,5 Y 4 / 3$ & $2,5 Y 3 / 3$ & sh st pt & $3 \mathrm{msbk}$ & $\begin{array}{l}\text { Strüktürel } \\
\text { gelișim }\end{array}$ \\
\hline Crk & $68+$ & 8.48 & 0.21 & 48.4 & 0.1 & $2,5 \mathrm{Y} 6 / 6$ & $2,5 Y 6 / 6$ & so ss ps & sg & Kireç miselleri \\
\hline
\end{tabular}

*: Strüktür: $1=$ zayıf; $2=$ orta; $3=$ kuvvetli; $\mathrm{sg}=$ tek dane; $\mathrm{m}=$ masif; $\mathrm{vf}=$ çok ince; $\mathrm{f}=$ ince; $\mathrm{m}=\mathrm{orta} ; \mathrm{c}=\mathrm{kaba}$; gr= granüler; $\mathrm{pr}=$ prizmatik; abk= köșeli blok; sbk= yarıöşeli blok, Kıvam: (Kuru) lo= gevşek; so= yumuşak; sh= hafif sert; h= sert; (Islak) so= yapışkan değil; ss= hafif yapışkan; st= yapışkan; po= plastik değil; $\mathrm{ps}=$ hafif plastik; $\mathrm{pt}=$ plastik, OM: Organik madde

arasında değişmekte ve bu oran özellikle profil içerisinde yüzeyden derine doğru inildikçe azalma göstermektedir. Yine marn ana materyal üzerinde oluşmuş olan Typic Haplustept toprakların $\mathrm{pH}$ değerleri 7.78 ila 8.60 arasında olup, hafif alkalin reaksiyonludur. Vertic Ustorthent de olduğu gibi derinlere doğru kireç miktarındaki artış Hue (ana spektral renk) $2.5 \mathrm{Y}$ olmasına karşılık value yüzeyden derine doğru artış göstererek renkte açılma meydana gelmiştir. Toprakların kireç içerikleri yüzeyde \% 11.6 iken, derinlikle artmakta ve ana materyalde \% 27.3'e çıkmakta. Profil içerisindeki organik madde içerikleri \% 0.1 ile \% 2.9 arasında değişmektedir. Vertic Calciustept topraklar ise diğer topraklarda olduğu gibi hafif alkalin reaksiyonludur. Buna karşın, profil içerisinde kalsifikayon olayı belirlenmiştir. Vertic Ustorthent topraklarda olduğu gibi bu topraklarında yüzeylerinde çatlaklıklar bulunmaktadır. Kireç içeriği profil içerisinde çok fazla değişkenlik göstermekte, bu durum renk değişiminde de fazla fark yaratmaktadır. Topraklarının pH's1 7.92 ile 8.48 arasinda olup, hafif alkalin reaksiyonludur. Organik maddenin ise yüzeyde \% 1.6 olup derinlere doğru azaldığı belirlenmiştir. Çalışmada ele alınan tüm topraklarda tuzluluk problemi bulunmamaktadır (Tablo 2).

Yamaç arazilerde yer alan 1 nolu profile ait toprakların büyük bir kısmı, yerçekimi kuvveti etkisinin yanı sıra dik eğimlere (\% 30'dan fazla) sahip olmaları ve yeterince bitki örtüsünce kaplı olmayan yerlerde toprak taşınımına maruz kalmaları nedeniyle çok sı̆̆ ve sı̆̆ toprak derinliğe sahiptirler. Yine bu topraklarda yüzeyde yüksek orandaki kil içeriği ( $\%$ 60) ve yaz aylarında meydana gelen çatlakların oluşumu, vertiklik özellik göstermesi dışında herhangi bir tanı horizonu bulunmamaktadır. Toprakların horizon oluşması için yeterli pedogenetik sürece sahip olmamas1 nedeniyle, bu topraklar toprak taksonomisi (Anonymous, 1999)'ne göre Entisol ordosuna; yamaç eğime sahip, sı̆̆ olmaları nedeniyle orthent alt ordosuna, nem rejiminden dolayı ustorthent büyük grup sınıfına ve yüzeyde görülen vertiklik özeliğinden dolayı da Vertik Ustorthent alt grup sınıfina yerleştirilmiş; Anonymous (2006) sinıflama sistemine göre ise Vertic Leptosol olarak sınıflandırılmıştır. Profil numaraları 2 ve 3 olan toprakların tanı horizonları (cambic ve calcic) sahip olmaları dolaysiyla Entisollerden daha ileri bir toprak oluşumu göstermeleri nedeniyle Inceptisol ordosuna ve toprak nem rejiminin ustic olması sonucu, Ustept alt ordosuna yerleştirilmişlerdir. Ayrıca, 2 no'lu profil $100 \mathrm{~cm}$ derinlik içerisinde bir fragipan veya duripan içermemeleri ve aynı derinlik içerisinde calcic veya petrocalcic horizonlarının olmaması neden ile, Haplustept ve 3 no'lu profil ise calcic horizon içermesi nedeniyle Calciustept büyük grup kategorik sınıfına yerleştirilmiştir. Alt grup seviyesinde ise 2 no'lu toprak profili büyük grup sınıfının tüm özelliklerini, 3 no'lu toprak profili ise toprak yüzeyinde vertik özellikler göstermesi nedeniyle sirasiyla Typic Haplustept ve Vertic Calciustept alt gruplarına yerleştirilmiş. Bununla beraber topraklar Anonymous (2006) siniflama sistemine göre ise Haplic Cambisol ve Calcaric Cambisol olarak sınıflandırılmıştır (Tablo 3). 
Tablo 3. Çalışma alanı toprak serilerinin Toprak Taksonomisi (Anonymous, 1999)'ne ve Anonymous (2006)'a göre siniflandirması

\begin{tabular}{lcccc}
\hline & \multicolumn{3}{c}{ Toprak taksonomisi } & \multirow{2}{*}{ FAO/ISRIC-WRB } \\
\hline Ordo & Alt ordo & Büyük grup & Alt grup & \\
\hline Entisol & Orthent & Ustorthent & Vertik Ustorthent & Vertic Leptosol \\
Inceptisol & Ustept & Haplustept & Typic Haplustept & Haplic Cambisol \\
& & Vertic Calciustept & & Calcaric Cambisol \\
\hline
\end{tabular}

\subsection{Kil mineralojisi}

Toprakların mineralojik kompozisyonlarını özelliklede kil çeşidi ve miktarı toprakların birçok fiziksel özelliklerini doğrudan etkilemektedir. Özellikle; sıkışabilirlik, plastiklik, şişme potansiyeli gibi indeks özellikler yüzde olarak simektit kil mineralinin miktarlarındaki artışa paralel olarak artış göstermektedir. Çalışma alanındaki dağılım gösteren farklı toprakların mineralojik bileşimlerini belirleyebilmek amacıyla yüzey ve yüzey altı toprak örneklerinde X-1şınları çözümlemeleri (XRD) yapılmıştır. Çalışma alanında hâkim kil minerali simektit grubu 2:1 tipi şişen kil minerallerinden montmorillanit olup, ikinci ve üçüncü derecede yaygın olarak gözlenen kil mineralleri ise nantronit ve kaolonit olarak belirlenmiştir. Yaygın pimer mineraller ise kuvars, kalsit, feldispat mineraller olarak tespit edilmiştir (Tablo 4 ve Şekil 1).

\subsection{Toprakların kıvam indeks özellikleri}

Kıvam limitleri, ince taneli toprakların sınıflandırılmasında, şişme ve aktivite özelliklerinin belirlenmesinde, mineralojik özellikleri hakkında fikir vermesi açısından önemli parametreler olarak değerlendirilmektedir. Aynı ana materyal üzerinde oluşmuş Entisol ve Inceptisol topraklara ait 12 adet toprak örneği üzerinde kıvam limitleri ve plastisite indeks değerleri belirlenerek değerlendirilmiştir. Elde edilen sonuçlar Tablo 5'te sunulmuştur. Tablo 5'ten görüleceği üzere, 3 no'lu profile ait ana materyalin bünyesi hariç tüm topraklar killi olarak sınıflandırılmış ve kil miktarı $\% \quad 41$ ile \% 71 arasında değişmektedir. Kil oranındaki bu değişim şişme ve plastiklilik özellik üzerinde de yansıması görülmekte olup kil oranı \% 49 üzeri olan örneklerde plastiklilik yüksek olarak belirlenirken, en düşük plastiklilik Vertic

Tablo 4. Çalışma alanına ait yüzey ve yüzey altı toprak örneklerinde belirlenen kil ve primer mineral çeşitleri

\begin{tabular}{|c|c|c|c|c|}
\hline Topraklar & Horizon & Derinlik & Kil minerali & Primer mineraller \\
\hline \multicolumn{5}{|c|}{ Profil-1 } \\
\hline \multirow{2}{*}{$\begin{array}{l}\text { Vertic } \\
\text { Ustorhent }\end{array}$} & Ap & $0-16$ & Montmorillanit, kaolinit & Kuvars, kalsit, feldispat, \\
\hline & $\mathrm{Ad}$ & $16-35$ & Montmorillanit, kaolinit & Kuvars, kalsit, feldispat \\
\hline \multicolumn{5}{|c|}{ Profil-2 } \\
\hline Typic & A & $0-28$ & Montmorillanit, nontronit, çok az kaolinit & Kuvars, kalsit, feldispat, mika \\
\hline Haplustept & $\mathrm{Bw}$ & $28-68$ & Montmorillanit, çok az kaolinit & Kuvars, kalsit, feldispat, mika \\
\hline \multicolumn{5}{|c|}{ Profil-3 } \\
\hline \multirow{2}{*}{$\begin{array}{l}\text { Vertic } \\
\text { Calciustept }\end{array}$} & A & $0-24$ & Montmorillanit, nontronit, çok az kaolinit & Kuvars, kalsit, feldispat, \\
\hline & $\mathrm{Bw}$ & $24-68$ & Montmorillanit, nontronit, çok az kaolinit & Kuvars, feldispat, kalsit \\
\hline
\end{tabular}

Calciustept'in ana materyalinde belirlenmiştir. Topraklar çoğunlukla birleştirilmiş toprak sınıflama sistemine göre CH (inorganik kil, yüksek plastisite), CL (inorganik kil, düşük plastisite) olarak belirlenmiştir (Tablo 5).

Kıvam limitleri, ince taneli zeminlerin sınıflandırılmasında, aktivite, şişme ve kil tipi gibi durumlarının tahmin edilmesinde kullanılan temel parametrelerdir. Likit limit ve plastik limit arasındaki ilișki iki limit arasındaki fark olarak tanımlanan plastiklik indeksi dikkate alınarak tanımlanır ve toprağın plastiklik gösterdiği nem içeriğini temsil eder. Likit limite karşılık gelen plastiklik indeksi plastiklik kartı olarak ifade edilir
(Wagner, 1957). Plastiklik kartı üzerinde bulunan A çizgisi likit limiti \% 20 nem içeriğinden keser ve eğimi 0.73 'tür. Plastisite kartı üzerinde işaretli bulunan toprakların genel mühendislik durumları hakkında fikir vermektedir.

Vertik Ustorthent, Typic Haplustept ve Vertic Calciustept toprakların hepsi kil bünye sınıfinda (Vertic Calciustept'in ana materyali hariç) olmalarına karşın bu değişimin nedeni örneklerin içerdiği kil oranı, kil mineralinin tipi ve fraksiyon içindeki dağılımlarıdır. Üç toprak çeşidi içerisinde en yüksek kil (\% 71) içeriğine sahip olan Vertik Ustorthent, \% 63 ile de en yüksek likit limit değeri vererek çok yüksek plastiklik göstermiştir. Vertic 

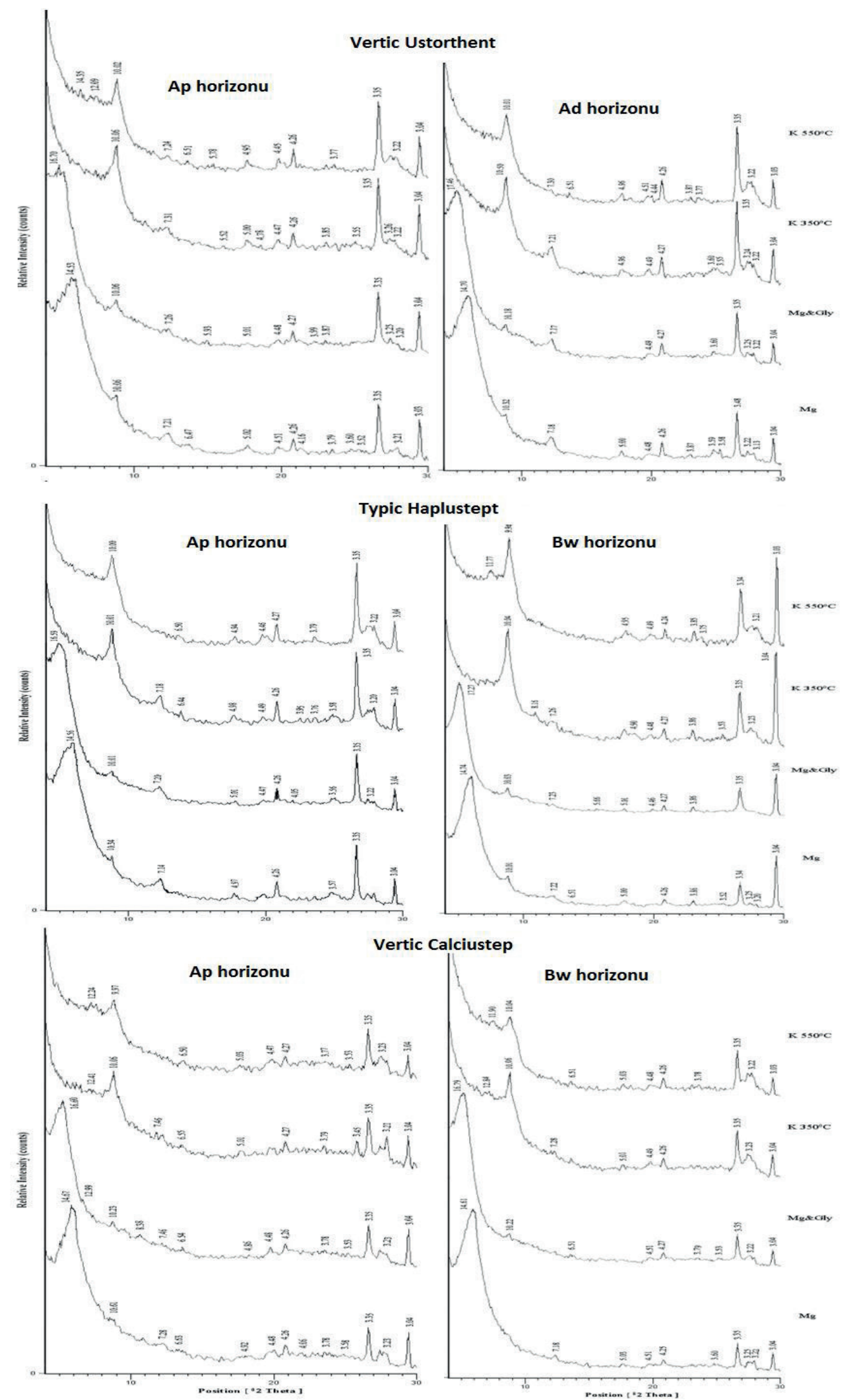

Şekil 1. Vertik Ustorthent, Typic Haplustept ve Vertic Calciustept topraklara ait yüzey ve yüzey altı horizonlarının kil grafikleri 
Tablo 5. Çalışma topraklarına ait tane büyüklük dağılımı ve kıvam indeks değerleri*

\begin{tabular}{|c|c|c|c|c|c|c|c|c|c|c|c|c|}
\hline \multirow{2}{*}{ Horizon } & \multirow{2}{*}{ / derinlik } & \multicolumn{4}{|c|}{ Bünye (\%) } & \multicolumn{4}{|c|}{ Atterberg limitleri (\%) } & \multirow{2}{*}{ USCH } & \multirow{2}{*}{ Şişme } & \multirow{2}{*}{ Plastiklik } \\
\hline & & $\mathrm{C}$ & $\mathrm{Si}$ & $\mathrm{S}$ & Sinif & $\mathrm{LL}$ & $\mathrm{PL}$ & IP & A & & & \\
\hline \multicolumn{13}{|c|}{ Proil-1/ Vertic Ustorhent } \\
\hline Ap & $0-16$ & 60 & 22 & 18 & $\mathrm{C}$ & 60 & 33 & 27 & 0.45 & $\mathrm{CH}$ & Orta & Yüksek \\
\hline $\mathrm{Ad}$ & $16-35$ & 71 & 20 & 9 & $\mathrm{C}$ & 63 & 37 & 26 & 0.37 & $\mathrm{CH}$ & Yüksek & Yüksek \\
\hline $\mathrm{AC}$ & $35-61$ & 55 & 22 & 23 & $\mathrm{C}$ & 52 & 32 & 20 & 0.36 & $\mathrm{CH}$ & Orta & Orta \\
\hline $2 \mathrm{Ck}$ & $61+$ & 41 & 34 & 25 & $\mathrm{C}$ & 42 & 24 & 18 & 0.44 & ML & Düşük & Orta \\
\hline \multicolumn{13}{|c|}{ Profil-2/ Typic Haplustept } \\
\hline A & $0-28$ & 50 & 19 & 31 & $\mathrm{C}$ & 52 & 26 & 26 & 0.52 & $\mathrm{CH}$ & Orta & Yüksek \\
\hline $\mathrm{Bw}$ & $28-68$ & 45 & 32 & 23 & $\mathrm{C}$ & 48 & 28 & 20 & 0.44 & CL & Düşük & Orta \\
\hline $\mathrm{Ck}$ & $68-97$ & 43 & 32 & 25 & $\mathrm{C}$ & 36 & 20 & 16 & 0.37 & CL & Düşük & Orta \\
\hline $\mathrm{Cr}$ & $97+$ & 41 & 39 & 20 & $\mathrm{C}$ & 48 & 24 & 24 & 0.59 & CL & Yüksek & Orta \\
\hline \multicolumn{13}{|c|}{ Profil-3/ Vertic Calciustept } \\
\hline $\mathrm{A}$ & $0-24$ & 46 & 22 & 31 & $\mathrm{C}$ & 41 & 25 & 16 & 0.35 & $\mathrm{CL}$ & Düşük & Orta \\
\hline $\mathrm{Bw}$ & $24-68$ & 49 & 18 & 33 & $\mathrm{C}$ & 57 & 28 & 29 & 0.59 & $\mathrm{CH}$ & Orta & Yüksek \\
\hline Crk & $68+$ & 24 & 47 & 29 & $\mathrm{~L}$ & 35 & 24 & 11 & 0.46 & $\mathrm{CL}$ & Düşük & Düşük \\
\hline
\end{tabular}

": C: Kil, Si: Silt, S: Kum, LL: Likit limit, PL: Plastik limit, IP: Plastiklilik indeksi, A: Aktivite değeri

Calciustept'in ana materyalinde ise en düşük kil içeriğinde (\% 24) yine en düşük (\% 35) likit limit değerini alarak düşük plastiklik gösterdiği tespit edilmiştir (Tablo 5).

Çalışma alanı toprakları plastisite kartı yani likit limit ve plastisite indeksi değerleri kullanılarak örnekler kart üzerine yerleştirilmiş ve birleştirilmiş toprak sınıflama sistemine göre sinıflandırıldığında ise örneklerin sahip olduğu bu indeks değerlerinin plastisite kartındaki dağılımları Şekil 2'de verilmiştir. Zemin özellikleri bakımından tüm toprak profillerinde birleşik sinıflama sistemine göre yüksek plastisiteli inorganik killer $(\mathrm{CH})$ olduğu sonucuna ulaşılmıştır.

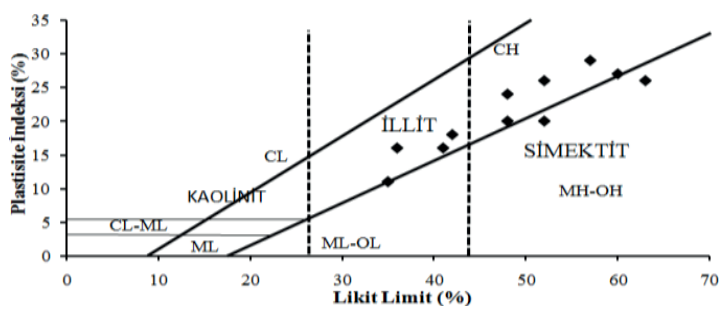

Şekil 2. Toprak örneklerinin plastisite kartı üzerindeki dağılımları ve Atterberg plastik ve likit

limit değerleri ile kil minerolojisi ilişkisi

Kil düzeyi \% 40’’n üzerinde olan örnekte yapılan plastik ve likit limit analiz sonuçları plastiklik indisi 30'un üzerinde, likit limit 50'nin üzerinde saptanırsa söz konusu toprağın hakim kil mineralinin smektit grubu kil minerali olduğu söylenebilir (Kapur ve Akça, 2015). Şekil 2'de görüldüğü gibi XRD sonuçlarının da ortaya koyduğu şekilde toprak profil örneklerimizin tamamının plastisite kartı üzerinde yoğunlaştığ bölge, hakim kil mineralinin smektit olduğu, bu minerali illitin takip ettiğini işaret eden bölge olarak görülmektedir. Ayrıca Gougazeh ve Al-Shabatat
(2013) alüvyal ve heyelanlı toprak materyallerini mineralojik ve fiziksel özelliklerini inceleyerek alüvyal materyalin likit limit değerini \% 20-40, plastiklik indeksi değerinin ise \% 7.3-16.3 arasında, heyelanlı materyalin ise sirasiyla likit limit ve plastiklik indeksi değerlerinin \% 28-58 ile \% 12-43 arasında değiştiğini gözlemleyerek, XRD analiz sonuçlarına göre de bu durumu destekler şekilde hakim kil mineralinin heyelanlı materyalde smektit olduğunu tespit etmişlerdir.

Altınbaş ve Zorba (1990), plastisite indisinin kil yüzdesine oranlanmasıyla elde edilen aktivite parametrelerinin, topraktaki kil miktarı ile kil mineral tipinin toprağın mühendislik özellikleri üzerine olan etkisinin ayrımlılığını yansıttığını; aktivite ile plastik limit arasında pozitif, kil arasında negatif ilişkiler saptandığını bildirmişlerdir. Çalışma alanı aktivite değerleri ise Skempton (1953) tarafindan, Gillot (1987)'e göre sınıflandırması yapılmış ve bu sınıflamaya göre üç alt gruba ait toprakların aktivite değerleri 0.35-0.59 arasında değişim göstererek, aktif olmayan killer olarak ifade edilmiştir. Bu durum kil yüzdesi fazla ve hâkim kil mineralinin smektit grubu kil minerali olmasına karşın, yine smektit grubu bir kil minerali olan nantronit kil mineralinin varlığından kaynaklanmaktadır. $\mathrm{Bu}$ mineral smektit grubu olmasına karşın su tutma ve diğer özellikler bakımından montmorillonit gibi özellikler göstermemektedir (Mitchell ve Soga, 2005). Esraa (2011) Irak Thi-Qra Üniversitesi topraklarında yaptığı çalışmasında, toprakların fiziksel ve mineralojik özelliklerini incelemiş ve yaygın kil mineralinin montmorillonit olarak belirlemiş, bunu illit ve kaolonit izlediğini bildirmiştir. Aynı çalışmada, aktivite değerlerini ise ortalamada (\% 80) aktif olmayan ve (\% 20) normal aktif killer olarak belirlemiştir. Toprakların şişme 
potansiyelleri de aktiviteleri ile yakından ilişki göstermektedir.

Toprak örneklerin Van Der Merwe (1964)'nin şişme potansiyeli sınıflama abağı üzerindeki dağılımları Şekil 3 ve Şekil 4'te verilmiştir. Her iki şekilde de görüldüğü gibi, toprak örneklerin çoğunluğu orta ve yüksek şişme potansiyeli bölgelerinde yer almasına karşılık, az miktarda düşük sınıf düzeyinde yer alan alanda dağılım göstermiştir.

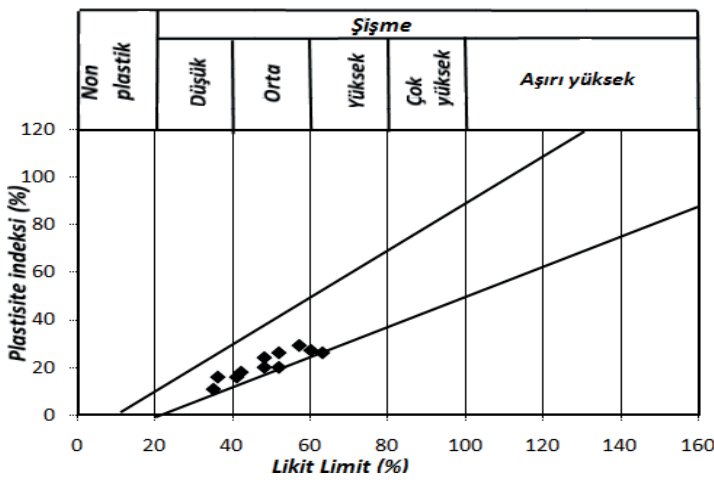

Şekil 3. Toprak örneklerinin Dakshanaman ve Raman (1973)'ın şişme potansiyeli abağı üzerindeki dağılımı

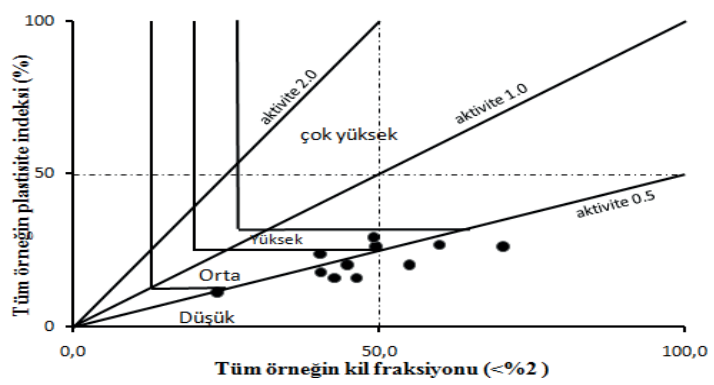

Şekil 4. Toprak örneklerinin Van Der Merwe (1964)'nin şişme potansiyeli abağı üzerindeki dağılımları

\section{Sonuçlar}

Bu çalışmada; aynı ana materyal üzerinde oluşmuş üç farklı alt grup düzeyinde sınıflandırılan Vertik Ustorthent, Typic Haplustept ve Vertic Calciustept topraklarına ait örneklerde, toprakların kil mineralojileri, mühendislik özellikleri ile birlikte bazı fiziksel ve kimyasal özellikleri incelenerek değerlendirilmiştir. Toprakların yüzey horizonlarında plastisite ve şişme değerleri orta ve yüksek olarak belirlenirken, ana materyalde bu durum orta ve düşük olarak belirlenmiştir. Yapılan çalışmada, bu toprakların birleştirilmiş toprak sınıfının CH (yüksek likit limitli kil) grubunda yer alması yüksek olasılıkla ortamdaki simektitin yüksekliğinden kaynaklanmaktadır. Topraklarının yüksek derecede şişme-büzülme zararına sahip olduğu ve yüksek plastiklik gösterdiği de tespit edilmiştir. Simektit grubu kil minerallerini içeren toprakların zemin açısından sorunlu olabileceği, bu açıdan gerekli kültürel önlemlerin alınması ve zemin mekaniği araştırmalarının daha detaylandırılması gerektiği öneri olarak düşünülebilmektedir.

\section{Kaynaklar}

Anonymous, 1992. Soil Survey Staff. Procedures for Collecting Soil Samples and Methods of Analysis for Soil Survey. Soil Survey Investigations Report I., U.S. Gov. Print. Office, Washington D.C., USA.

Anonymous, 1993. Soil Survey Staff, Soil Survey Manuel. USDA Handbook, No: 18, Washington D.C., USA.

Anonymous., 1999. Soil Survey Staff, Soil Taxonomy. A Basic of Soil Classification for Making and Interpreting Soil Survey. USDA Handbook No: 436, Washington D.C., USA.

Anonymous, 2006. FAO/ISRIC. World References Base for Soil Resources, World Soil Rep., No: 103, Rome.

Altınbaş, Ü., Zorba, M., 1990. Yamanlar Dağı yöresi (İzmir) kireçsiz kahverengi büyük toprak grubunun zemin mekaniği yönünden kimi mühendislik özellikleri üzerine araştırmalar. Ege Üniversitesi Ziraat Fakültesi Dergisi, 26(1): 28-37.

Atterberg, A., 1911. On the investigation of the physical properties of soils and on the plasticity of clays. Internationale Mitteilungen für Bodenkunde, 1: 10-43 (In German).

Baver, L.D., 1966. Soil Physics. John Wiley and Sons Inc., New York.

Blake, G.R., Hartge, K.H., 1986. Bulk density and particle density. In: A. Klute (Ed.), Methods of Soil Analysis, Part I, Physical and Mineralogical Methods, $2^{\text {nd }}$ Edn., Soil Science Society of America Agronomy Monograph, Madison, pp. 363-381.

Bouyoucous, G.J., 1951. A Recalibration of Hidrometer for Making Mechanical Analysis of Soils. Agronomy Journal, 43(9): 434-438.

Boyraz, D., Sar1, H., 2012. Tekirdağ Değirmenalt1Muratlı kavşağ 1 çevre yolunu olușturan katenadaki toprakların fiziksel ve zemin özelliklerinin değerlendirilmesi. Tekirdăg Ziraat Fakültesi Dergisi, 9(3): 68-78.

Canbolat, M.Y., Barik, K., Özgül, M., 1999. Erzurum yöresinde farklı ana materyaller üzerinde oluşmuş üç toprak profilinin kıvam limitleri ve şişme-büzülme karakteristikleri. Atatürk Üniversitesi Ziraat Fakültesi Dergisi, 30(2): 121-129.

Canbolat, M.Y., Öztaş, T., 1997. Toprağın kıvam limitleri üzerine etki eden bazı faktörler ve kıvam limitlerinin tarımsal yönden değerlendirilmesi. Atatürk Üniversitesi Ziraat Fakültesi Dergisi, 28(1): 120129. 
Casagrande, A., 1958. Classification and identifications of soils. Transactions American Society Civil Engineer, 113(3): 901-930.

Çağlar, K.Ö., 1958. Toprak İlmi. Atatürk Üniversitesi Ziraat Fakültesi Yayınları, No: 10, Ankara.

Dakshanaman, V., Raman, V., 1973. A simple method of identifing an expansive soil. Soil and Foundation, 13(1): 97-104.

Dumbleton, M.J., West, G., 1966. Some factors affecting the relation between the clay minerals in soils and their plasticity. Clay Minerals, 6(1): 179-193.

Esraa, A.M.A., 2011. Swelling Potential and Mineralogy of Thi-Qar University Soil. Journal of Thi-Qar University, 1(7): 1-15.

Gillot, E.J., 1987. Clay in Engineering Geology, 2nd Edn., Elsevier, Amsterdam, pp. 484.

Gougazeh, M., Al-Shabatat, A., 2013. Geological and geotechnical properties of soil materials at Tannur dam, Wadi Al Hasa, South Jordan. Journal of Taibah University for Science, 7: 216-224.

Gürsoy, F.E., Dengiz, O., 2018. Farklı iki ana materyal üzerinde oluşmuş vertisol toprakların morfolojisi, mineralojik özellikleri ve sinıflaması. Anadolu Tarım Bilimleri Dergisi, 33(2): 162-169.

Head, K.H., 1984. Manual of Soil Laboratory Testing, Volume I. Soil Classification and Compaction Tests (Third edition) Whittles Publication, London, pp. 422.

Jackson, M.L., 1958. Soil Chemical Analysis. Prentice Hall Inc., Englewood Cliffs, N.J.

Kapur, S., Akça, E., 2015. Toprak Etüd Haritalama El Kitab1, Minerolojik ve Mikromorfolojik Özellikler. T.C. Gıda Tarım ve Hayvancılık Bakanlığı, Tarım Reformu Genel Müdürlüğü, Ankara, s. 210-223.

Le Villio, M., Arrouays, D., Deslais, W., Droussin, J., Le Bissonnais, Y., Clergeot, D., 2002. Interest of the compost as a source of organic matter to restore and maintain physical properties of French soils. 17. World Congress of Soil Science, 14-21 August, Bangkok, No: 57, p. 1529.
Mbagwu, J.S.C., Abeh, O.G., 1998. Prediction of engineering properties of tropical soils using intrinsic pedological parameters. Soil Science, 163(2): 93-102.

Mitchell, J.K., Soga, K., 2005. Fundamentals of Soil Behavior. 3rd Edition. Wiley, New York.

Saka, A.H., 1997. Mineralojik Analizlerde X-Işını Toz Kırınım Yönteminin Temel Prensipleri ve Laboratuvar Şartlarının Standardizasyonu. Maden Teknik Arama Genel Müdürlüğü Yayını, Ankara, s. 234.

Skempton, A.W., 1953. The colloidal activity of clays. 3rd International Conference on Soil Mechanics and Foundation Engineering, 16-27 August, Zurich, 1: 57-61.

Smith, C.W., Hadas, A., Dan, J., Koyumjisky, H., 1985. Shrinkage and Arterberg limits in relation to other properties of principal soil types in Israd. Geoderma, 35(1): 47-65.

Sowers, G.F., 1965. Consistency. Methods of Soil Analysis, Part I, American Society of Agronomy, Madison, Wisconsin, U.S.A.

Sönmez, K., Öztaş, T., 1988. Iğdır Ovas1 yüzey topraklarının bazı fiziksel ve kimyasal özellikleri ile mekaniksel özellikleri mekaniksel özellikleri arasındaki ilişkiler. Atatürk Üniversitesi Ziraat Fakültesi Dergisi, 19(1-4): 145-153.

Wagner, A.A., 1957. The use of the unified soil classification system by the bureau of reclamation. 4th International Conference on Soil Mechanics and Foundation Engineering, 12-24 August, London, Vol. 1, p. 125.

Van Der Merwe, D.H., 1964. The Prediction of heave from the plasticity index and percentage clay fraction of soils. Civil Engineering in South Africa, 6(6): 103106.

Whitting, L.D., Allardice, W.R., 1986. Principles of XRay Diffraction. In: A. Klute (Ed.), Methods of Soil Analysis, Part 1, ASA Publications, pp. 331-359. 